\title{
The comparing of the operation time of second cesarean section with the closure or non-closure of parietal peritoneum in the first cesarean section: Result in omental adhesions to the scarpa fascia?
}

\author{
Nejla Gultekin* \\ Obstetric and Gynecology Department, Sehir Hospital, Turkey
}

\begin{abstract}
Background: Was the operation time of the second cesarean section affected from the technics of the operation in the first cesarean section.

Objectives: We estimated that the operation time in the second cesarean section would be more longer by non-closing of the parietal peritoneum than the closure. Firstly, the non-closure of theparietal peritoneum was seemd to gain time during the first cesarean section. However we compared the operation time of the second cesarean section of non-closure and closure.
\end{abstract}

Study design: This was a retrospactive study. The study had two groups of the second cesarean sections of patients who had closure and non- closure of parietal peritoneum in the first cesarean section. The closure of pariatel peritoneum was control group with 1308 patients and the non-closure of any peritoneum was case group with 740 patients. In the both groups, the operation time and the amount of the adhesions of the omentum to the scarpa fascia were compared.

Result: The nonclosure of the parietal peritoneum may gain time during the first operation but the nonclosure will casues the more adhesions of omentum to the scarpa fascia and the time of the second repeated cesarean will be longer. For this reason, the recover in second operation will be late in non- closure patients.

Conclusion: This study was very important experiment about operation tehcniques with doing the second operation to the same patients. This study should be done in multiple centers with more number of patients in the World.

\section{Introduction}

The wellbeing of the baby and mother is cornerstone of the obstetric. The delivery was perfomed with vaginal birth for many years. By increasing use of antibiotics and operations numbers, the mortality and morbidity of baby and mothers had got importance after vaginal deliveries. The surgeons choosed the cesarean sections $(\mathrm{C} / \mathrm{S})$ than any normal vaginal deliveries to decrease the fetal and mother death rates. Nowadays, the rising in cesarean section numbers that are unneccesary is a major problem in the global world. Many countries try to use different procedures to increase the vaginal birth. All policies, for the encouraging patients and doctors for the vaginal deliveries are not enough to decrease the numbers of unneccesary caeserean sections in the world. In 2008, 3.18 million additional cesarean section were needed and 6.20 million unneccesary cesarean section were done [1$3]$. On the other hand, the cost of global excess cesarean section was estimated to be 2.32 billion US dolars with the cost of global needed cesarean section about 432 million US dolars [1]. Although the aim of cesarean section is the decreasing of newborn and mother mortality and morbidity rates, the complications of the cesarean section can be result in disability or death of the baby and mother [3-5]. Since 1985, a C-section rate of $10-15 \%$ has been deemed optimum by international health-care community [6]. When C- section rates rise towards $10 \%$ across a population, maternal and newborn deaths decrease; when they are higher than $15 \%$, there is no evidence of reduced morbidity [6]. Even though, the C- section rates rise up 70\% in some countries, the standard evidence-based quidelines are not established [3,2]. The C-section can be repeated operations for same women. For this reason, the postoperative complications of $\mathrm{C}$ - section are important for woman's life. A C-section is one of the most frequently perfomed major surgical procedure in the worldwide, accounting for anything up to $70 \%$ of deliveries [2]. In 1989 , general rate of $\mathrm{C} / \mathrm{S}$ was around $5 \%$ to $20 \%$ of all deliveries [7]. In addition to higher C- section rates, there are many possible ways of performing a C-section and operative technique [2]. All surgeon generally use their own or their preference operator procedures. But there is huge conflict about the $\mathrm{C}$-section techniques. The point is that repeated C- section operations and no cut off number in one patient. So that, a women can have more than one C-section in their life that means steadily increased risk of complications and disabilities of operations.

In gynecologic operations, the closing of the peritoneum is a standard procedure [2] but it is not in a C-section operation because the closing of peritoneum has some disadvantages in repeatetion of

Correspondence to: Nejla Gultekin, Obstetric and Gynecology Department, Sehir Hospital, Eğricam Mah. Argün Marina Sitesi, B Blok Kat: 11, Diare:21, Yenişehir/Mersin, Turkey, Tel: +90 532 7995516, E-mail: nejlagultekin@yahoo.com

Key words: closure, non-closure, peritoneum, cesarean section

Received: June 02, 2017; Accepted: July 17, 2017; Published: July 20, 2017 
Gultekin N (2017) The comparing of the operation time of second cesarean section with the closure or non-closure of parietal peritoneum in the first cesarean section: Result in omental adhesions to the scarpa fascia?

operations. . The peritoneum is a thin membrane made of primitive cells called mesothelium and supported by a thin layer of connective tissue [2]. It covers abdominal and pelvic cavity that is called parietal peritoneum and covers external surface of internal organs which is termed visceral peritoneum [2]. During the C-section both layers of peritoneum is incised and the question on that point is both layers should be closed or not. The cited reasons for closure of peritoneum include restoration of anatomy and reapproximation of tissue, reduction of infection by reestablishing an anatomical barrier, reduction of wound dehiscence, reducing hemorrhage, minimisation of adhesions and continuation of what is thought as standard. For this reason, the closure of peritoneum in all C-section operations are seem to be reasonable. However the experiments in vivo using dogs [8] and rats [9] have shown no difference in wound strength whetter the peritoneum is closed or not and have sugested that peritoneal adhesions may be more extensive when the peritoneum is closed, presumably as a result of foreign body reaction from the suture materials [2]. The suture may cause peritoneal tissue ischemia at the edge which may delay healing and serve as a cause of intraperitoneal adhesions and febrile morbidity [2]. In addition, randomized controlled trials in general surgery of peritoneal closure or non closure with vertical abdominal incisions $[2,10]$ had shown no significant short-term difference in postoperative complications or pain scores. In operative gynecology, controlled trials of peritoneal non-closure in vaginal hysterectomy [11] abdominal and radical hysterectomy and lymphadenectomy [12] had demonstrated no difference or an improvement in short -term postoperative morbidity if peritoneum was not closed. In the former study [12] where peritoneal nonclosure was compared with closure during lymphadenectomy for ovarian cancer, peritoneal non closure reduced adhesion formation. In contrast to the closure of peritoneum, the non-closure of peritoneum showed better short term effects on postoperative care in a new experiment [13]. In addition, the closure of both parietal and visceral peritoneum had disadvantages on vital signs that were deciling in duiresis, increasing in risk of hypertansion [14]. All researches showed the good evidence about non-closure of peritoneum in C-section. Howerver in 2015, one experiment figured out the much more adhesions in non-closure of peritoneum than the closure[15]

In most experiments, about closure and non closure of peritoneum, observed the short-term and long-term advantages and disadvantsges. In our research, we try to gather information about what is going on in the second C- section with the non closure of parietal peritoneum by comparing with closure of parietal peritoneum. In experiments, the non-closure of peritoneum is seemed to be time saving and cost saving and have no any adhesions to cause infertility. However, our point in this experiment is the observing of the affect of nonclosure of the parietal peritoneum in second C- section. We expecting the nonclosure of parietal peritoneum will cause adhesions but it will not affect the fertility but those adhesions may cause prolonged operation time, recovery, rising of the postopertive pain in the second C-section.

\section{Methods}

\section{Including criteria}

We have including criteria to measure the operation time directly;

Age between 20-40 years old

Body mass index more than 19

No any intraabdominal operations including C- sections.

No IVF or ovulation induction treatments
No preterm vaginal delivery, premature rupture of membrane, placenta previa, hypertension or gestational diabetus in the pregnancy

No malpresentation of the fetus

No oligohydromnios or polyhydromnios of the fetus

No fetal or uterine anomalies.

No preeclampsia or eclampsia

All case and control groups were done under spinal anesthesia ( no epidural and general anesthesia)

\section{Excluding criteria}

We had some excluding criteria that will effect the operation time;

The age below 20 and more than 40 years old.

The previous intraabdominal operations

Reccurrent C-section operations

IVF or ovulation induction treatments

The C- section in the preterm, premature rupture of membrane, placenta previa,plasenta acreate, increate or percreate

The hypertension or gestational diabetus in the pregnancy

The Malpresentation of the fetus

The oligohydromnios or polyhydromnios of the fetus

The presence of the fetal or uterine anomalies.

The presence of the preeclampsia or eclampsia

\section{Objectives}

In our experiment, we retrospectively grouped the $\mathrm{C} / \mathrm{S}$ operations in to two group as a case and control group. In the control group, 1308 patients had primary $\mathrm{C} / \mathrm{S}$ with the closure of parietal peritoneum and undergo second $\mathrm{C} / \mathrm{S}$ by observing the adhesion of omentum to scarpa fascia. On the other hand, 740 patients were taken primary $\mathrm{C} / \mathrm{S}$ with nonclosure of peritoneum and their second $\mathrm{C} / \mathrm{S}$ were done to see adhesions of omentum to the scarpa fascia in the case group. The indications of primary $\mathrm{C} / \mathrm{S}$ were elective, fetal distress, cephalopelvic disproportion, the arrest in the active or latent phase.

The major aim was comparing the operation time in the second $\mathrm{C} / \mathrm{S}$ of the case and the control group by affect of omental adhesions to scarpa fascia.

\section{Methods}

In this study, we done first C- section by closing or non-closure of the parietal peritoneum and than we measure the operation time and observed the adhesions of the omentum to the scarpa fascia in the second C-section.

We had 1308 patients (pts) in the control group and 740 patients in the case group. The case group was subdivided into two groups as group B1 that had adhesions of the omentum to the scarpa facsia in one space and the adhesions in multiple space. We had 378 patients in the group B1 and 362 patients in group B2.

In the control group ( the closure of parietal peritoneum ) there was no any omental adhesion to the scarpa fascia. In the case group ( the non-closure of the parietal peritoneum) there was adhesions of the 
Gultekin N (2017) The comparing of the operation time of second cesarean section with the closure or non-closure of parietal peritoneum in the first cesarean section: Result in omental adhesions to the scarpa fascia?

omentum on the scarpa fascia. In all groups we gathered the operation time in the second $\mathrm{C} / \mathrm{S}$. We also grouped the omental adhesions according to body mass index and we compare the operation time in both normal and higher body mass index. In control group, the operation time of second C/S who have bady mass index 20-25 was between 10 minute $(\mathrm{m}) 40$ second( $\mathrm{s})-13 \mathrm{~m} 25 \mathrm{~s}$, the body mass index more than 25 was $12 \mathrm{~m} \mathrm{24s-15m} \mathrm{30s.} \mathrm{In} \mathrm{case} \mathrm{group,} \mathrm{group} \mathrm{B1} \mathrm{that} \mathrm{is}$ the adhesion of omentum to scarpa fascia on one point , the operation time was $15 \mathrm{~m} 32 \mathrm{~s}-18 \mathrm{~m} 02 \mathrm{~s}$, in group B2 which was the adhesions are in multiple amount on scarpa fascia, the time was $25 \mathrm{~m} 30 \mathrm{~s}-27 \mathrm{~m} 34 \mathrm{~s}$. On the other aspect, the opertion time of case group in the second C/S

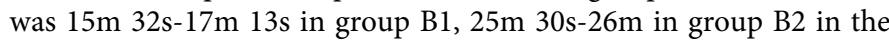
body mass index between $20-25$., the operation time was around $17 \mathrm{~m}$ $54 \mathrm{~s}-18 \mathrm{~m} 2 \mathrm{~s}$ in the goup B1 and $26 \mathrm{~m} 1 \mathrm{~s}-27 \mathrm{~m} 34 \mathrm{~s}$ in group B2 In the body mass index more than 25 .

\section{Statistical analysis}

In our research, we analysed the data with SPSS (Statistical Package for Social Sciences) by using Windows 22.0 program. During evaluation istatistical methods were used as numbers, percents, mean or standard devition. The relation between variable analized with kikare.

The comparing of two variable groups was done by t-test, more than two variable with one way Anova test. After Anova test, Scheff test as post-hoc was used for determining of differences.

For independent variable pearson corolation was done. The confidential interval was $95 \%$.

\section{Result}

The operation time is important for the recovery, short hospitalization and better managment of the pain. The postoperative pain is other subject that is effected with the tecnique of the operation. In our experiment, we tried to figure out the operation time of second $\mathrm{C}$-section after the closure or non-closure of the parietal peritoneum in the first caeserean section to find the statistical importance on recovery, hospitalization and pain. . Our experiment was retrospective case- control study. Firstly, we showed the distribution of features of groups in Table 1 . Totaly we have 2048 patients, $63,9 \%$ in the control group and $18,5 \%$ in case $\mathrm{B} 1$ and $17.7 \%$ in case B2. In all group, the clasification by BMI was done and $52,1 \%$ of patients had BMI 25 and below, $47.9 \%$ of patients had BMI more than 25 .

The division of the case and control groups by their BMI showed in the Table 2. The BMI 25 and below was 56\% in the control group, $72 \%$ in the case B1 group and $17 \%$ in the case B2 group. The BMI above the 25 was $44 \%$ in the control group, $28 \%$ in the case B1 group and $82,9 \%$ in the case B2 group.

When we compare the case group and control group about BMI (Table 2) there is positive relation with BMI and the adhesion of omentum to the scarpa fasia $\left(\mathrm{X}^{2}=244,947 ; \mathrm{p}=0,000<0.05\right)$. The control group of BMI 25 and below was $732(56 \%)$ patients, BMI above 25 was 576 (44\%).In the case group of B1 which was 25 and below consisted of $272(72 \%)$ patienst and $106(28 \%)$ patients above 25. In th case group B2, the number of patients who had body mass index 25 and below was $62(17 \%)$ and $300(82.9 \%)$ above the more than 25 BMI.In this table, we understood that the adhesions of omentum to scarpa fascia in the non-closure of the parietal peritoneum was in higher amount in the BMI above 25.
Table 1. The distribution of the features of groups

\begin{tabular}{|c|c|c|c|}
\hline Table & Groups & Frequency(n) & percentage (\%) \\
\hline \multirow{3}{*}{ Group } & Control & 1308 & 63,9 \\
\cline { 2 - 4 } & Case B1 & 378 & 18,5 \\
\cline { 2 - 4 } & Case B2 & 362 & 17,7 \\
\cline { 2 - 4 } & Total & 2048 & 100,0 \\
\hline \multirow{3}{*}{ BMI Grup } & 25 and below & 1066 & 52,1 \\
\cline { 2 - 4 } & More than 25 & 982 & 47,9 \\
\cline { 2 - 4 } & Total & 2048 & 100,0 \\
\hline
\end{tabular}

Table 2. BMI of groups

\begin{tabular}{|c|c|c|c|c|c|c|c|c|}
\hline & & \multicolumn{2}{|c|}{ Control } & \multicolumn{2}{|c|}{ Case B1 } & \multicolumn{2}{|c|}{ Case B2 } & \multirow{2}{*}{$\mathbf{p}$} \\
\hline & & $\mathrm{n}$ & $\%$ & $\mathbf{n}$ & $\%$ & $\mathrm{n}$ & $\%$ & \\
\hline \multirow{2}{*}{ BMI } & $\begin{array}{l}25 \text { and } \\
\text { below }\end{array}$ & 732 & $\% 56,0$ & 272 & $\% 72,0$ & 62 & $\% 17,1$ & \multirow{2}{*}{$\begin{array}{c}\mathrm{X}^{2}=244,947 \\
\mathrm{p}=0,000\end{array}$} \\
\hline & Above 25 & 576 & $\% 44,0$ & 106 & $\% 28,0$ & 300 & $\% 82,9$ & \\
\hline
\end{tabular}

The age group and BMI comparing of control and case group showed the statistical impartonce (Table 3 ). This is one way (Anova) test $(\mathrm{F}=53.471 ; \mathrm{p}=0<0.05)$. The higher $\mathrm{BMI}$ was seen in the case B2 group that had more adhesion of the omentum than others. In addition, the age was higher also in case B2 but it was not higher than control group in case B1 group as in BMI. The origin of the differences was determined by post-hoc analysis. In the case B2, the age was higher $(32,140 \pm 3,050)$ than the control group's age $(30,370 \pm 4,357)$. Besides, the age of control group $(30,370 \pm 4,357)$ higher than the case b1 $(29,280 \pm 2,030)$. The case B2 age $(26,870 \pm 1,869)$ higher than the control $(25,840 \pm 1,810)$. The BMI of the control group $(25,840 \pm$ $1,810)$ was higher than the BMI of case B1 $(25,200 \pm 0,871)$. The BMI of case B2 $(26,870 \pm 1,869)$ was higher than the BMI of the case B1 $(25,200 \pm 0,871)$. The differences between the groups, BMI was higher in the more adhesions. On the other hand, the comparing of BMI and age in groups showed that the mean age was 30 ages in the control group and 29 ages in case B1 and the 32 ages in the $\mathrm{B} 2$. That means our experimental groups were almost at the same ages. In the nonclosure of the parietal peritoneum, the adhesions would like to be in the older and more fat women (Table 4).

In our experiment, the mean operation time were compared in all groups and the one way (Anova) analysis was used. The mean operation time differences was statistical important between groups $(\mathrm{F}=20535,041 ; \mathrm{p}=0<0.05)$. The origin of the differences in groups was determined with post-hoc analysis. The mean operation time of case $\mathrm{B} 1(1002,840 \pm 42,727)$, was higher than the mean operation time of the control group $(759,480 \pm 78,114)$. The mean operation time of the case B2 $(1586,410 \pm 54,028)$ was higher than the control group $(759,480 \pm$ $78,114)$. The mean operation time of the case B2 $(1586,410 \pm 54,028)$ was higher than the case $\mathrm{B} 1(1002,840 \pm 42,727)$. This experiment was designed to measure the operation time in closure and nonclosure of parietal peritoneum. This table showed that, the operation time was directly related with the adhesions. More adhesions means that more operation time because of disection of adhesions caused the loss of the time. If the parietal peritoneum is not closure during the first $\mathrm{C}$-section, the time of second C-section was longer than the closure of the parietal peritoneum (Figure 1). In addititon, if the adhesion of omentum was in multiple areas the time of operation was most longest (Table 5).

In the control group, the operation time and BMI had positive relationship moderately $(\mathrm{r}=0.583 ; \mathrm{p}=0,000<0.05)$ and the operation time and age had positive relationship slightly $(\mathrm{r}=0.428 ; \mathrm{p}=0,000<0.05)$.

In the case B1 group; the operation time and BMI had minimal relationship positively $(\mathrm{r}=0.132 ; \mathrm{p}=0,010<0.05)$. However, there was no any relation between the operation time and age $(\mathrm{p}>0.05)$. 
Gultekin N (2017) The comparing of the operation time of second cesarean section with the closure or non-closure of parietal peritoneum in the first cesarean section: Result in omental adhesions to the scarpa fascia?

Table 3. The comparing of groups by BMI and age

\begin{tabular}{|c|c|c|c|c|c|c|}
\hline \multirow{2}{*}{ Groups } & Control & Case B1 & Case B2 & \multirow{2}{*}{$\mathbf{F}$} & \multirow[b]{2}{*}{$\mathbf{p}$} & \multirow{2}{*}{ diff } \\
\hline & Mean \pm Ss & Mean \pm Ss & Mean \pm Ss & & & \\
\hline Age & $30,370 \pm 4,357$ & $29,280 \pm 2,030$ & $32,140 \pm 3,050$ & 53,471 & 0,000 & $\begin{array}{l}3>1 \\
1>2 \\
3>2\end{array}$ \\
\hline BMI & $25,840 \pm 1,810$ & $25,200 \pm 0,871$ & $26,870 \pm 1,869$ & 92,866 & 0,000 & $\begin{array}{l}3>1 \\
1>2 \\
3>2\end{array}$ \\
\hline
\end{tabular}

Tablo 4. Mean Operation Time in Groups

\begin{tabular}{|c|c|c|c|c|c|c|}
\hline \multirow{2}{*}{ Groups } & Control & Case B1 & Case B2 & \multirow{2}{*}{$\mathbf{F}$} & \multirow{2}{*}{$\mathbf{p}$} & \multirow{2}{*}{ diff } \\
\hline & Mean \pm Ss & Mean \pm Ss & Mean \pm Ss & & & \\
\hline Operation time & $759,480 \pm 78,114$ & $1002,840 \pm 42,727$ & $1586,410 \pm 54,028$ & 20535,041 & 0,000 & $\begin{array}{l}\text { CaseB1 }>\text { Control } \\
\text { CaseB2>Control } \\
\text { CaseB2>CaseB1 }\end{array}$ \\
\hline
\end{tabular}

Table 5. The comparision of operation time with BMI and age in control and case groups

\begin{tabular}{|c|c|c|c|}
\hline \multirow{2}{*}{ Control Group Operation Time } & & BMI & Age \\
\hline \multirow{2}{*}{ Case B1 Group Operation Time } & $\mathrm{r}$ & $0,583^{* *}$ & $0,428^{* *}$ \\
\cline { 2 - 4 } & $\mathrm{p}$ & 0,000 & 0,000 \\
\cline { 2 - 4 } & $\mathrm{r}$ & $0,132^{*}$ & 0,090 \\
\hline \multirow{2}{*}{ Case B2 Group Operation Time } & $\mathrm{p}$ & 0,010 & 0,081 \\
\cline { 2 - 4 } & $\mathrm{r}$ & $-0,031$ & 0,059 \\
\cline { 2 - 4 } & $\mathrm{p}$ & 0,554 & 0,266 \\
\hline
\end{tabular}

$*<0,05 ; * *<0,01$

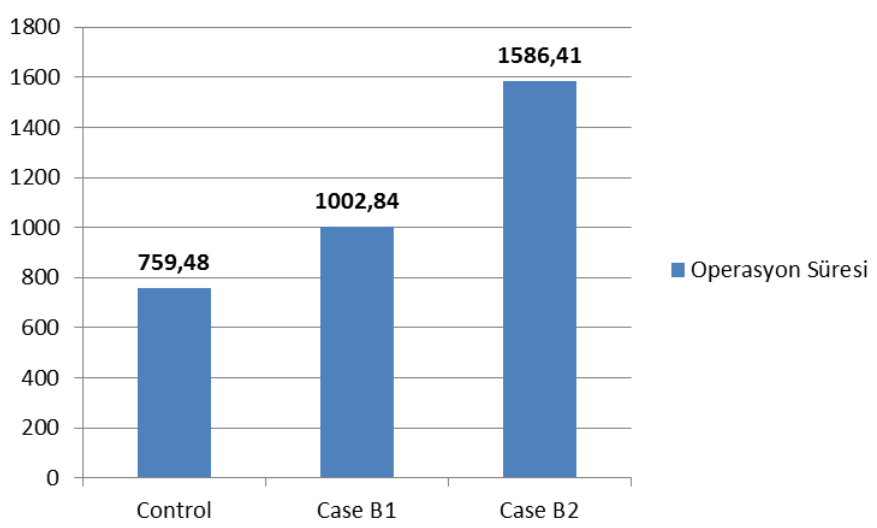

Figure 1. The comparision of operation time with the groups in the Bar-chart

In the case B2 group; the operation time and BMI had no any statistical importance $(\mathrm{p}>0.05)$. The operation time and age had no statistical importance $(\mathrm{p}>0.05)$. The comparision of the operation time with age and BMI was statistically important only in control group so that the closure of the parietal peritoneum in the first $\mathrm{C}$-section prevent the adhesion of the omentum to the scarpa fascia and it makes short operation time in the second C- section in the BMI 25 and below (table 9 ). At the end of this study, we figured out the time of hospitalization, recovery rate and the postoperative pain was not changed in the control and case group.

\section{Discussion}

The closure of peritoneum is all the time discussed between the surgeons. There are many studies about the techniques of C-section and gynecological operation, the effect of the closure or non-closure of the peritoneum on vital signs [12], hospitalization, recovery rate, pain and postoperative infection $[2,10,12]$. All those studies have almost the same result that the closure of peritoneum causes the more morbidity than the non-closure $[5,7,9]$. Our study is a powerfull study as a performing of first and second C-section with the same surgeon and it shows the advantages and disadvantages of the two different $\mathrm{C}$-secion techniques by opening of the same patients with the same surgeon. Our study is not focused on the short-term or long-term advantages or disadvantages of closure or non-closure as other studies $[5,9,12,13]$, we try to pay attention to repetition of operation and the effect of closure or non-closure on repeated operations. We do not demonstrate the any differences in recovery, hospitalization, postoperative infection or pain between case and control groups. On the other hand we do not design our study for comparing of those parameters and we want to see that what is going on intraabdominaly with closure or non-closure.

Because of relation between the operation time and adhesion of omentum to scarpa fascia, the nonclosure of the peritoneum may gain time during the operation but the nonclosure will casues the adhesions of omentum to the scarpa fascia and the time of second C-section will be longer than the normal cases. So that we don't recoment to choose the nonclosure of the parietal peritoneum in the first $\mathrm{C}$ - sections.

\section{Conclusion}

As a result, we don't recomend the nonclosure of parietal peritoneum in the first $\mathrm{C}$ - section. The nonclosure may be performed in the last C-section. This study is a retrospective study. For this reason the result my affected from the biasis. This study should be done in multi- center prospectively.

\section{References}

1. Gibbons L, Belizan JM, Lauer JA, Betran AP, Merialdi M, et al. (2010) The global numbers and cost of additionally needed and unnecessary caeserean section performansper year: overuseas a barrier to universal coverage. World Health Report 2010; Background paper 30. Geneva: World Health Organization, 2010.

2. Bamigboye AA, Hofmeyr GJ (2014) Closure versus non-closure of the peritoneum at caesarean section: short- and long-term outcomes. Cochrane Database Syst Rev: CD000163. [Crossref]

3. Temmerman M (2016) Caesarean section surgical techniques: all equally safe. Lancet 388: 8-9. [Crossref]

4. Bauserman M, Lokangaka A, ThorstenV, Tshefu A, Goudar SS, et al. (2015) Risk factors of maternal death and trends in maternal mortality in low and middle-income countries: a prospective longitudinal cohort analysis. Reprod Health 12: 55. [Crossref]

5. Souza JP, Gulmezoglu A, Lumbiganon P, Laopaiboon M, Carroli G, et al. (2010) Caesarean section without medical indications is associated with an increased risk of adverse short -term maternal outcomes: the 2004-2008 WHO Global Survey on Maternal and Perinatal Health. BMC Med 8: 71.

6. Betran AP, Torloni MR, Zhang J, Ye J, Mikolajczyk R, et al. (2015) What is the optimal rate of caesarean section at population level? A systemic review of ecologic studies. Reprod Health 12: 57. [Crossref] 
Gultekin N (2017) The comparing of the operation time of second cesarean section with the closure or non-closure of parietal peritoneum in the first cesarean section: Result in omental adhesions to the scarpa fascia?

7. Anderson GM, Lomas J (1989) Recent trends in cesarean section rates in Ontario. CMAJ 141: 1049-1053. [Crossref]

8. Parulkar BG, Supe AN, Vora IM, Mathur SK (1986) Effects of experimental nonclosure of peritoneum on development of suture line adhesions and wound strength in dogs. Indian J Gastroenterol 5: 251-253. [Crossref]

9. Kyzer S, Bayer I, Turan, H, Chaimoff C (1986) The influence of peritoneal closure on formation of intraperitoneal adhesions: an experimental study. Int J Tissue React 8: 355-359.

10. Ellis H (1977) Wound Healing. Ann R Coll Surg Engl 59: 382.

11. Lipscomb GH, Ling FW, Stovall TG, Summitt RL Jr (1996) Peritoneal closure at vaginal hysterectomy: a reassessment. Obstetric Gynecol 87: 40[Crossref]
12. Kadanali S, Erten O, Kücüközkan T (1996) Pelvic and periaortic pertioneal closure or non-closure at lymphadenectomy in ovarian cancer: effects on morbidity and adhesion formation. Eur J Surg Oncol 22: 282-285. [Crossref]

13. Kurek Eken M, Özkaya E, Trahan T, Içöz S, Eroglu S, et al. (2016) Effects of closure versus non-closure of the visceral and parietal peritoneum at cesarean section: does it have any effect on postoperative vital signs? A prospective randomized study. J Matern Fetal Neonatal Med 5: 1-5. [Crossref]

14. Tabasi Z, Mahdian M, Abedzadeh-Kalahroudi M (2013) Closure or non-closure of peritoneum in cesarean section: outcomes of short-term complications. Arch Trauma Res 1: 176-179. [Crossref]

15. Takreem A (2015) COMPARISON OF PERITONEAL CLOSURE VERSUS NONCLOSURE DURING CAESAREAN SECTION. J Ayub Med Coll Abbottabad 27 78-80. [Crossref]

Copyright: $@ 02017$ Gultekin N. This is an open-access article distributed under the terms of the Creative Commons Attribution License, which permits unrestricted use, distribution, and reproduction in any medium, provided the original author and source are credited. 